\title{
Make-or-Buy Decision Criteria in Pakistan Pharmaceutical Industry; a case of Albert Pharmaceutical Industry
}

\author{
Mahnoor Fatima ${ }^{1}$
}

Received: 15 December 2021

Accepted: 2 February 2022

\begin{abstract}
The goal of this research is to look into how Pakistan Pharmaceutical industries took make o buy decision. The "Make-or-buy" decision is an important choice in an organization. This decision can affect costs, competencies, and capability in the organization. The data has been collected from specialists of Albert manufacturing company in Pakistan. The questionnaire has been distributed to seven decision-makers of the Albert Pharmaceutical industry. Albert Pharmaceutical Industry mostly follows the decision-making criteria for core activities because it is a government requirement that all documents related to the manufacture and testing of medicines shall be submitted to Pakistan's Drug Regulatory Authority (DRAP). Because these are life-saving drugs, the government must take all precautionary measures. We have observed the relationship among the Resource-Based View, Cost Reduction, Environmental Uncertainty, and Financial Benefits, and the Decision-Making Criteria, on the other hand. The results of our study reveal that the Resource-Based View, cost reduction, and financial benefits are highly related to the decision-making criteria, whereas environmental uncertainty does not influence them at all. The outcomes of this study have also stated that making criteria is beneficial for the pharmaceutical industry. We also implement the regression analysis to see which factor has the greatest influence on the decision-making criteria, disclosing the Resource-Based View to be the most influential variable. Also, participants specify that they prefer manufacturing because they have most of the requisite resources and machinery along with human resources, organizational resources, and financial resources.
\end{abstract}

Keywords: Make-or-buy, resource-based view, decision-making criteria JEL Code: M31

\footnotetext{
${ }^{1}$ Hailey College of Commerce, University of the Punjab, Lahore fmahnoor09@gmail.com ORCID No: 0000-00028454-9230

InTraders International Trade Academic Journal Vol.4 Iss.2 e-ISSN-2667-4408

www.intraders.org 


\section{Introduction}

Pakistan is a developing country and the Ministry of National Health Services legislation and Coordination is in full control of them. Pharmaceutical law is ruled through the Drug Regulatory Authority of Pakistan (DRAP), which ensures that the Drugs Act of 1976 is followed. The national essential medicine list (NEML) in Pakistan is primarily based on WHO standards and promotes standard medications; however, the whole report is generally only seen in public health centers (Rasheed et al., 2019).

The initiative of the Prime Minister's Health Insurance Program to establish rules for manufacturing and strict penalties for drug-related law violations are just a few examples of how the government is critical to maintaining health insurance. Pakistan had no Pharmaceutical industry when it achieved independence. The only way of fulfilling people's medical needs is export which is a very expensive way. But now many national and international pharmaceutical industries are working in Pakistan (Dawood, 2012).

In the current business environment, it is critical for most pharmaceutical industries to address and concentrate to their overall corporate capabilities to obtain a higher advantage. This can help the organization achieve its desired organizational goals. In this regard, many pharmaceutical companies implement a strategy of concentrating on their core activities, which requires defining important functions and evaluating which could be made in-house or outsourced. Industries flip to conducting their operations themselves, consisting of human resources (HR), production, packing, warehousing, transportation, and substances planning, in the reaction of those permanently changing needs and increasing complexities (Bastani et al., 2019).

The well-known motivations of enforcing these operations can be categorized into three types: enhancing abilities, increasing profit, and reducing expenses. Core competencies, on the other hand, are the outcome of a combination of capabilities, routines, and firm-specific resources. A firm's performance is uncertain as environmental conditions such as competition and market dynamics play significant roles.

The traditional nature of business operations requires the majority of economic activities are conducted inside the organization. However, with the evolution of markets and increased variety InTraders International Trade Academic Journal Vol.4 Iss.2 e-ISSN-2667-4408

www.intraders.org 
of specialized decision-making criteria within these markets, the opportunity for outsourcing many non-core activities has grown significantly. An important phase in making in-house decisions or the process of outsourcing deals with the identification and assessment of potential risks.

The make-or-buy decision is one of the most crucial choices for any manufacturing organization. Typically, production corporations have loads of components, each of which may be made inresidence or outsourced. The outsourcing decisions are not best limited to substances and additives of a product but additionally apply to non-manufacturing support which includes assisting supply. For many businesses, the number of outsourcing choices is great. Besides cost and profit, outsourcing decisions additionally consider method issues, efficiency, and hazard dimensions associated with providing high-quality, lead times, and adequate transportation performance. If any of these elements are considered together, a procurement decision may be extremely complicated, having an impact on the firm's profitability. Hence, a bad decision can lead to inadequate organizational effectiveness (Venkatesan, 1992; Welch \& Nayak, 1992).

The make-or-buy choice is one of the toughest duties faced by industries. Therefore, it necessitates extensive knowledge to evaluate the types of trade-offs, to identify all the available resources, and to make a decision that balances the organization's brief and long-term objectives. Furthermore, as organizational standards and marketplace circumstances change, this choice might also need to be taken in a complete one-of-a-kind manner within the future (McIvor et al., 2014).

Within corporations, due to strategic implications, the choice to make or buy is being given special attention. The choice to make or buy can frequently be a primary determinant of profitability, making a significant improvement to the organization's economic health (Yoon et al., 1994). Over the last few years, there is an increase in the number of organizations that outsource. The reason behind this trend refer to the risk related to a "make" approach, because of fast marketplace changes and the lack of pliability that characterizes in-house production (Hayes $\&$ Abernathy, 2007). Although, the trend to outsource parts that were previously manufactured in-house can result in an unexpected charges' increase, with many businesses failing to integrate the make-or-buy choice into the overall manufacturing approach (Probert et al., 2002).

InTraders International Trade Academic Journal Vol.4 Iss.2 e-ISSN-2667-4408

www.intraders.org 
Consequently, making it a crucial business strategy in which the firm is most involved, organizations have usually sought approaches to acquire an aggressive advantage over their potential competition to serve the need to respond to marketplace changes; although the current quite aggressive environment in which today's businesses operate acts as a robust stimulus for companies when choosing whether to outsource or not to outsource, an organization must understand several factors that may affect its performance by outsourcing.

Eventually, Albert pharmaceutical company, and also other top pharmaceutical companies in Pakistan have implemented manufacturing processes. This study seeks to bridge the gap through Resource-Based View, cost reduction, Environmental Uncertainty, Financial benefits Relationship with Decision-Making Criteria of Albert pharmaceutical company. Furthermore, this study will go thoroughly to identify how Albert Pharmaceutical followed the decisionmaking method and our main focus is to find if the decision, taken in the methodological terms of the company, is beneficial or not.

\section{Literature Review}

Various studies are available in the field of Make-or-Buy decision, of which all have mixed results. Most of the studies use a model for the determination of the suitability and costeffectiveness of their decision. In this study, we highlight the way in which decisions are taken in Pakistan's industrial sector.

Starting in the early seventies, purchasing from corporations was done primarily to obtain best prices, with other elements such as high quality and transportation being taken into consideration. Moreover, in so many circumstances, a substantial wide variety of elements along with transport reliability, technical capability, value functionality, and economic stability of the supplier had been now overlooked. Several businesses have implemented a competitive strategy regarding make-or-buy decisions, with many companies deciding to buy rather than make for short-term efficiency gains and company development (Ford et al.,2009).

Outsourcing has shifted its focus from peripheral activities such as cleanliness, serving, and security to more important business activities such as design, manufacturing, marketing, human resource management, and transportation (McIvor, 2000, 2009). When deciding whether to

InTraders International Trade Academic Journal Vol.4 Iss.2 e-ISSN-2667-4408

www.intraders.org 
outsource or insource, it is important to consider financial issues, market issues, reliance, and the availability of employees and equipment (Damme \& Amstel, 1996).

In practice, many firms have no method for evaluation in the process of decision making. According to Edward Davis, many corporations base their outsourcing on overhead costs. The choice of which additives to outsource is made by using ascertaining what's going to store maximum overheads expenses, in preference to on what makes the most long-run businesses sensibility (Davis, 1992).

\section{Making Criteria}

"Make" is the approach which should be followed in order to preserve the manufacturing process in-house. On the contrary, if the corporation is presently outsourcing the production, then it could desire to internalize it eventually. It is additionally crucial to preserve any present-day benefit by further developing the competency in order to limit the danger of competition. Ideally, an organization desires to have aggressive benefits in as many of its center activities as feasible (McIvor et al., 2016).

Making-or-purchase cost evaluation means identifying the cost to procure an element and comparing that value to the expenses involved by the item's purchase. The buying decision must be made whether all the costs associated with the buying decision, including transaction and coordination costs, are smaller than the production expense (Arya et al., 2008).

It is important to differentiate between the essential and semi-essential activities of the firm. It is also important to include a core activity to outline what is anticipated. Key interests are valuable to the corporation when it comes to correctly serving the desires of the capable customer in all marketplaces. The customer perceives the activity to be valuable, and thus it becomes a primary determinant of aggressive profit. Making the distinction between important activities and unessential activities is complex, and there should be ensured that long-term strategic issues and benefits are analyzed (McIvor et al., 2016).

Tayles and Drury (2001) stated that descriptive elements, as well as dishonest providers, the desire to govern production and quality of elements, as well as retain knowledge within the organization, will contribute to a decision. Other aspects include layout privacy, the ability to strengthen manufacturing, and workload pressure variability (Burt et al., 2010).

InTraders International Trade Academic Journal Vol.4 Iss.2 e-ISSN-2667-4408

www.intraders.org 
Making criteria consist of Cost, Quality, Time Experience, Financial position, Workload, Design secrecy, Production control, Environmental protection, Legislation, and Distribution control (Moschuris, 2014).

\section{Environmental Uncertainty}

Environmental uncertainty can be defines as a company's inability to accurately determine the outcome in their selection (Wong et al., 2011). Environmental uncertainty typically has influences on the supply chain's overall result and dictates which aggressive factor should be highlighted and reviewed to establish a prevailing aggressive approach (Premkumar et al., 2005).

To maintain a competitive advantage, a successful manufacturing firm must consider whether a proper supply chain strategy is required to align with distinct environmental uncertainty. Evaluating and monitoring an organization's environment is critical for making correct choices and modifying techniques to a constantly changing context (Sun et al., 2009).

According to Anderson and Weitz (1986), environmental uncertainty has an adverse influence on both make or purchase choices. Certainly, creating and implementing policies to an external actor is difficult in an uncertain environment. Even so, wholly-owned corporations face similar challenges in coping with environmental uncertainty.

In this vein, corporations producing goods with rapid technological changes will gain from outsourcing, because they minimize the risk of never repaying their sunk costs as innovative technology emerges (Bartel et al., 2014).

\section{Resource-Based View}

The resource-based view (RBV) examines many aspects while considering threats and opportunities. From the resources point of view, a company creates the capabilities and competitive advantage for a specific business interest. RBV defines resources as physical and intellectual property inside the corporation. The useful resource-based view is entirely based on the concept of efficient resources (Barney, 1991).

In $\mathrm{RBV}$, the company compares its available resources with those of its competitors and attempts to have a few more resources than the competitor, giving him an edge over the competitors (Neves et al., 2014). According to Barney (1991), a significant factor that affects producing InTraders International Trade Academic Journal Vol.4 Iss.2 e-ISSN-2667-4408 
competitive benefits must be investigated based on the following criteria: price, desirability, rareness, and business enterprise. Moreover, the researcher believed that the corporation must be organized to maximize its resources and abilities.

The specialized technique is the basic function due to which a corporation gains the competitive edge. The techniques and other aspects that are not specialized can be outsourced. This summarizes that RBV is used to comprehend how the company's capabilities expand and influence its rank and overall effectiveness (Eric et al., 2019).

\section{Financial Benefits}

During the last three years, numerous types of research have been conducted by researchers in addition to assessing the financial condition with the assistance of various profitability ratios by employing statistical analysis techniques. Business overall output analysis refers to the methods required to fully assess a firm's capacity and obstacles using the connection between the heads of financial statements and the balance sheet (Panday, 1992).

The financial evaluation is defined as an investigation of causal relationships in terms of economic role and profit margins. The financial evaluation consists of three steps: Selecting, Relating and Evaluating financial records (Hingorani et al., 1973).

The major purpose of economic evaluation is to learn about the organization's fiscal overall effectiveness and control function, as reflected within the economic statistics and reports (Hampton, 1986). Aside from fiscal evaluation, the selection of a location is also important within the powerful asset utilization and cost reduction topics (Schumacher \& Sathaye, 1999).

\section{Cost Reduction}

Starting within the late 1970s and extending during the 1980s, most firms trusted conventional price reduction, which means that a group of crash applications concentrate on slicing prices via relowering payrolls and downsizing (Richardson, 1988). It is also surprising how firms can save sufficient resources to support additional expenses while still reaching the profit target and developing a feature for other organizations that might make that component (Akeem, 2017).

A conventional fee discount application is usually a distress tactic centered on employees. It is caused in reaction to an instantaneous danger, which includes poor performance, lack of InTraders International Trade Academic Journal Vol.4 Iss.2 e-ISSN-2667-4408

www.intraders.org 
contracts, or price reductions. Some of those packages (mainly offshore retreat and diversification, both of which might be explained below) are booked with the desire of escaping to places wherein hard work and center fees are inexpensive. While those conventional techniques often lessen costs straight away, the associated reduction of the value of human belongings sets the level for the failure of abilities, in the long run, five regularly used traditional COSI Deduction programs are defined within the sections under their effectiveness (Skinner, 1989).

The phrases cost saving and value discount sound quite similar to a commonplace man, but their meanings are different. The cost-saving way to simply lessen the production fee by any means can be made through the use of raw cloth, with the aid of products, or even through wrong storage while applying price reduction without compromising the product quality. Cost reduction is decreasing the quantities of money spent on manufacturing and wages so that it will generate greater profit for the enterprise whilst preserving the quality of the product (Yadav et al., 2013).

\section{Case Study}

Most of the national industries are operating in Pakistan and their majority has chosen to outsource. The number of industries that carry on the whole manufacturing process in developing countries is small. In developed countries, research on Make and Buy is being conducted mostly by using a specific model for the determination of what decision is beneficial to their industry. Therefore, the primary goal of this research is to investigate the Making process of any Pakistan industry. So, we selected the Pharmaceutical industry as it plays a vital role in people's lifesaving and it is important for developing countries because the pharmaceutical industries in Pakistan own the manufacturing process. This is why we selected the Albert Pharmaceutical industry and collected data from the decision-maker and have knowledge about their decision-making choices and results.

\section{Data and Methodology}

Management is included in the decision-making process, given its responsibility of examining the criteria on which is based. This research reveals a case study approach; we assume that the management occupying senior positions within the pharmaceutical industry are more knowledgeable about the environment, strategies, and financial performance. Therefore, our 
research is based upon primary data and secondary data, also known as the mixed method. The data was collected by questionnaire, given that an online survey was directed to an Albert pharmaceutical industry of Pakistan. The top executive of the Albert pharmaceutical industry was asked to respond to the survey, on the assumption that they have know-how regarding firms' strategic issues. The survey guide concerning questions included Resource-Based View, cost reduction, Environmental Uncertainty, financial benefits that affect Decision-Making Criteria. In order to give an insight not only into the making of service-related activities (such as resources and accounting), Albert pharmaceutical industry was chosen as the sample for this study and also allowed us to scrutinize the dynamics of manufacturing.

The sample consists of 7 people, of which there are 6 males and 1 female. Data included 14.3\% female respondents $85.7 \%$ male respondents. Moreover, the age of $85.7 \%$ of the total respondents ranged from 26-30 and the rest of 14.3\% ranged from 30-40. All the respondents were post-graduated and their work experience in Albert pharmaceutical company ranged from 1 to 5 years (for $14.3 \%$ ), 6 to 10 years (for $71.4 \%$ ), and the rest of $14.3 \%$ of the total respondents' experience was 10 years or above. The total data was collected from the top 7 executives of the Albert pharmaceutical industry.

The analysis of the data is based on a quantitative technique. The Structured Questionnaire is designed as a Tool for data collection. When the Questionnaire is adjusted, it is compulsory to measure the validity and quality of the questionnaires. However, the validity of this questionnaire has been approved by the concerned professional. The questionnaire is developed based on the Five-Step Likert Scale, which includes Strong disagree, Disagree, Neutral, Agree, and Strongly Agree, and a linear scale which includes very high to very low. We collected primary data through questionnaires and secondary data through previous research and data available on the internet. To begin with, the technique used for the sampling is non-random sampling in the cross-sectional time. The analysis of collected data is done through the software SPSS. The Study setting has been conducted in Natural Environment with Minimal Interference.

\section{Measures}

Within this research, we have concluded that the resource-based view, cost reduction, environmental uncertainty, financial benefits are independent variables, whereas the dependent

InTraders International Trade Academic Journal Vol.4 Iss.2 e-ISSN-2667-4408

www.intraders.org 
variables are the decision-making criteria of Albert pharmaceutical company. In order to keep the exploratory nature of this research, we elaborated detailed hypotheses and the decisions have not been examined before. Consequently, the hypotheses were tested to investigate the relationship between the independent and the dependent variables.

\section{Decision-making criteria}

Multiple conflicting criteria in the higher cognitive process are evaluated by a subdiscipline of research, expressly through multiple-criteria decision analysis. The stocks usually carry a high risk of losing cash that has the potential to transfer high returns, but managers propose to reduce the risks while recording high returns. By evaluating conflicting decision criteria which are typical because of price, quality simply increases in value. This analysis of make-or-buy demonstrates that the two-dimensional approach can be used in determining the make-or-buy decision. In industry, the price of providing services and client satisfaction are the basic conflicts

in decision-making criteria. Significantly, the dynamic nature of analysis issues is captured through the planned methodology. The criteria are time-dependent and distinctive assumptions are made according to relative priorities by the model which only performs a time-dependent assessment of make-or-buy alternatives. In the proposed questionnaire submitted in Albert pharmaceutical industry, 11 items were designed to measure decision-making criteria. The respondents were asked to rate accordingly the impact of each criterion on a make-or-buy dilemma during the online survey by using a five-point Likert scale ( 1 for very low, 5 for very high). The value of Cronbach's Alpha for these dimensions is .890 .

\section{Environmental uncertainty}

Environmental uncertainties refer to the fact that firms affect chain performance as the future has unpredictable results under conditions of inaccurate choices. Sometimes environmental uncertainty determines the competitive factors in the market. Therefore, it should be evaluated and used as a winning competitive strategy. In unpredicted environments, writing and implementing contracts with external agents can cause trouble in the future. When investigating the decision-making criteria in changing environments, the sales fluctuations are very important to drive the pharmaceutical industry. Environmental uncertainty harms the production, purchase, and sales of products. This circumstances can force the management towards make-or-buy 
decisions, the company being interested in minimizing sales fluctuations based on production inhouse.

There were created five dimensions to test the environmental uncertainty. Each item was tested by using a five-point Likert-type scale, ranging from 1 "very low" to 5 "very high." These dimensions are similar to those used by many developed to measure the following:

H1. There is a relationship between Environmental uncertainty and "making" criteria.

Opting for an in-house approach will grant higher profit by saving investments in some areas. However pharmaceutical industry can invest in required areas through in-house operations and these activities might perform by maintaining these variables. The pharmaceutical organization should pay attention to resource-based views (land, building, equipment, money etc.) and should also add a lot of facilities.

\section{Resource-Based View}

Five items were developed on a Likert scale from (1) "strongly disagree" to (5) "strongly agree" and individual responses were collected to measure the Resource-based review. Each individual was asked to indicate their view on the "making" decision criteria. Accurate data is collected from respondents. The value of Cronbach's Alpha for these dimensions is .932. It was ensured that supported resources claim that we want to include capabilities and competencies in the analysis since they need an impression on the potency to govern the other structures. The square measures the complementary ability for innovation during making in-house. One assumes selfseeking as a basic characteristic of human behavior. The resources should be used properly. The selection of assets in the governance structure has, therefore, to be created cut back. On the other hand, the second perspective focuses on the matter of restricted knowledge of resources. It is usually not possible to transfer information to alternative persons. The hypothesis was developed to measure the following:

H2. There is a relationship between Resource-Based View and "making" criteria.

\section{Cost reduction}

The costs for the availability of production will have to be funded even in times when demand for the product is low and the facility might be underutilized. Essentially, making in-house InTraders International Trade Academic Journal Vol.4 Iss.2 e-ISSN-2667-4408

www.intraders.org 
comprises the cost of manufacturing, profit margin, and internal resources. In Pharmaceutical Companies Cost reduction is done by a real and permanent reduction in the cost of products. They attempt to attain real savings in the price of distribution, administration, production, and commercialism. In the pharmaceutical industry, potential savings are buried; it is an attempt to excavate within the standards by planned efforts. The market lacks the dynamic approach however price management always needed standards intact of the variances. Cost management also seeks adherence and challenges in the price reduction standards. In pharmaceutical companies, the purpose of cost reduction is to check whether or not there's any chance of saving the prices incurred materials, labor, and factory overheads. Cost reduction begins wherever price management ends. Price management brings the actual harmonically change with the planned targets of making in-house.

A six-item construct was used to investigate assess cost reduction under making decision criteria. Each item was tested through a five-point of Likert-type scale (1) "strongly disagree" to (5) "strongly agree" The value of Cronbach's Alpha for these dimensions is.877. The hypothesis was developed to measure the following:

H3. There is a relationship between cost reduction and "making" criteria.

\section{Financial benefits}

There are several ways pharmaceutical industries can get financial benefits by a greater focus and by increasing the availability of the drugs the greatest value can be attained. It can also be attained by Assets that produce more sellable product volume which operates longer between outages. The progressive volume made by additional reliable instrumentality carries a bigger margin of profit as a result of the fastened prices that were already unfolded across the baseline volume. Although the business isn't during a sold-out capability and therefore further volume isn't required, there are unit opportunities to create changes to operative shifts to cut back prices. When financial benefits are improved, maintenance prices are reduced often dramatically. Systems in pharmaceutical companies yield vital price reductions. Finally, to get financial benefits, assets area unit productive requires focus and our focus will yield higher high efficiencies. Funds might be deployed elsewhere for the nice of the business that may ordinarily be won't be replaced. However, in the pharmaceutical industry to create financial benefits focus

InTraders International Trade Academic Journal Vol.4 Iss.2 e-ISSN-2667-4408

www.intraders.org 
lead to modifications to the instrumentality to boost its reliability over the life of assets, and therefore newer instrumentality isn't needed anymore

Five dimensions are developed critically and effectively to measure financial benefits. Each dimension was rated with the help of a five-point Likert-type scale (1) for "strongly disagree" to (5). "Strongly agree" The value of Cronbach's Alpha for these dimensions is .910. The hypothesis was developed to measure the following:

H4. There is a relationship between financial benefits and "making" criteria.

In the research, the poll for reliability test is created on SPSS for this study that inquiries both independent variables and dependent results. The reliability is tested on SPSS software under restrictions of thumb rule, the estimation of Cronbach's alpha should be more than 70\% which means 0.7. The value shows that the research of the data is reliable and satisfactory as the Cronbach's alpha is 0.842. In this research, all five dimensions' reliability is based on Cronbach's Alpha value that should be greater than 0.70 . However, in the result of the reliability test, the amount of Cronbach's Alpha of all the items is more than 0.70. So, the results have strong individual loadings on each dimension and show reliability and clarity in the conceptual structure.

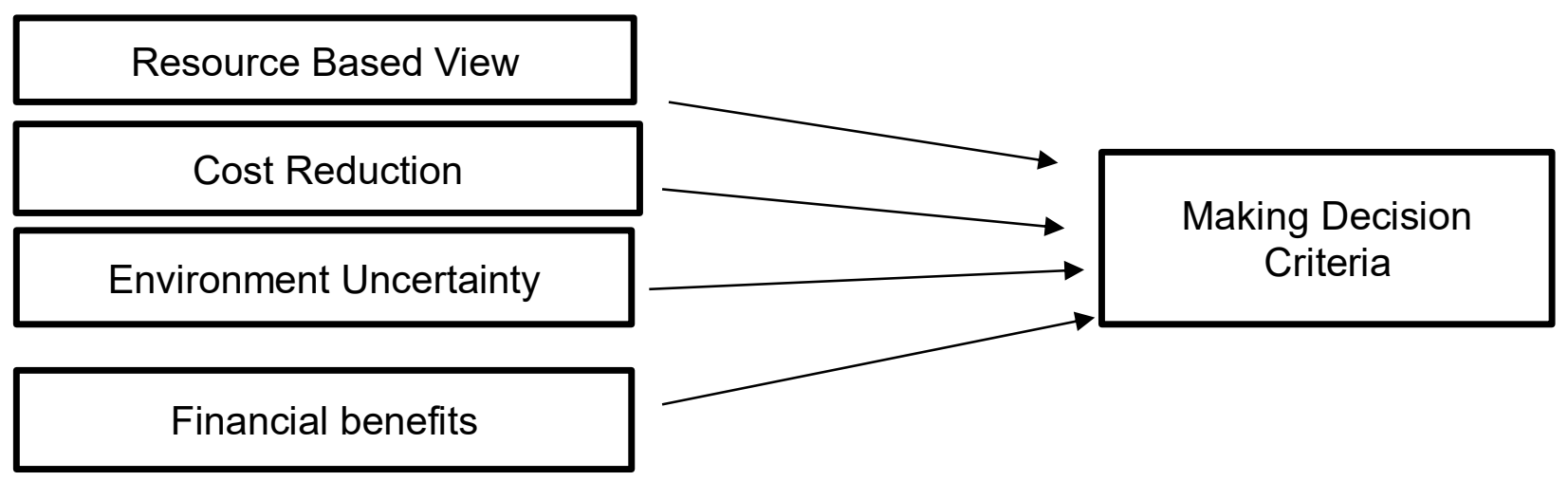

\section{Conceptual Model}




\section{Analysis/Results}

We analyzed the above responses to identify is there any relationship among Resource-Based View, cost reduction, Environmental Uncertainty, the financial benefits Handling on Making Decision Criteria the dimensions to represent the relationships among the dependent and independent variables.

In analysis, The One-Sample Kolmogorov-Smirnov Test was used to test the normality of dimensions. The thumb rule of normality analysis is if the level of significance a more than 0.05 then the data is normal and if the level of significance a less 0.05 than data is not normal. 05 . The significance (2tailed) of Making Decision Criteria is 1.000 which is a $>0.05$. The significance (2tailed) of Environment Uncertainty is .803 which is a>0.05. The significance of (2tailed) Resource-Based View is .983 which is a $>0.05$. The significance (2tailed) of cost reduction is .905 which $\mathrm{a}>0.05$. The significance (2tailed) of the financial benefits is.828 which is $>0.05$. Since the data is normal because the significance level of factors in data is greater than 0.05 . The test results indicate that data is normal and the analysis is appropriate.

In our research, the model used for the correlation analysis computed the following information (principal components take values noted with double asterisk).

InTraders International Trade Academic Journal Vol.4 Iss.2 e-ISSN-2667-4408

www.intraders.org 
Table 1 Correlation Table

\begin{tabular}{lllllll}
\hline Sr. No & Variables & $\mathbf{1}$ & $\mathbf{2}$ & $\mathbf{3}$ & $\mathbf{4}$ & $\mathbf{5}$ \\
\hline $\mathbf{1}$ & $\begin{array}{l}\text { Environment } \\
\text { uncertainty }\end{array}$ & 1 & & & & \\
$\mathbf{2}$ & Resource-based review & .078 & 1 & & & \\
$\mathbf{3}$ & Cost reduction & .188 & $.976^{*}$ & 1 & & \\
$\mathbf{4}$ & Financial benefits & .139 & $.975^{*}$ & .958 & 1 & \\
$\mathbf{5}$ & Making criteria & .24 & $.992^{* *}$ & $.974^{* *}$ & $.953^{* *}$ & 1 \\
\hline
\end{tabular}

**Significant is at the $1 \%$ level of significance (2-tailed).

* Significant at the $5 \%$ level of significance (2-tailed).

In $\mathrm{H} 1$ we failed to reject the null hypothesis, there is no relationship between Environment uncertainty, and making criteria.

In environment uncertainty, the Decision-maker may know the alternative that in which outcome it should be used but the condition of certainty always exists. The future is always unpredictable under the condition of uncertainty the cause and effect can occur on a daily routine. The day-today operations could be affected by environmental uncertainty but it does not affect making criteria. Under such conditions accurate and measurable and reliable information accordingly is available to the pharmaceutical industry. However, Environment uncertainty does not relate to making criteria and the variables do not have a relation with each other.

IN $\mathrm{H}_{2}$ we accept the alternate hypothesis as there is a highly significant relationship between the Resources based view and making criteria.

The setting should be introduced to bring innovation by using specialized potential and resources we already have in the pharmaceutical industry to compete with threats and rivalry in the market. However, it's different to deal with or adopt new traits, functions, or skills it's easier to use new 
opportunities competencies, and victimization resources, which we already have. Resources based view mode focus most on resources and supporters different structure strategy development

In $\mathrm{H} 3$ we accept the alternate hypothesis as there is a highly significant relationship between cost reduction and making criteria

A systematic examination of functions and assessment of the techniques is done for cost reduction. The various fields created investigation channels to test the performance improvement to increase the value of particular products and services to reduce cost and increase efficiency level through analysis pharmaceutical companies. However, it helps pharmaceutical companies to achieve cost for the greatest possible value. Hence, to analyze all aspects of an existing product/service for specific functional requirements should determine the minimum cost in Albert pharmaceutical company.

In hypothesis $\mathrm{H} 4$ we accept the alternate hypothesis as there is a highly significant relationship between financial benefits and making criteria.

The financial benefits lead to stability. Only the stability in operations in the industry can bring an increase in reliability and efficiency in performance which can bring financial benefits to the industry. The continuous method in pharmaceutical industries can realize not only the quality loss because of unstable operative excursions. This reduction in scrap prices and the stoppage of material wastes in the industry include financial benefits. The steadiness of the method should be reduced to reduce the speed. Instrumentality effectiveness, quality, availability and turnout performance can therefore reliability can also bring positive impact on all the factors of financial benefits.

Therefore, our correlation result shows that these factors financial benefits, Resource-based view and cost reduction have a highly significant positive relationship with "making" criteria.

\section{By implementing regression, we also find which factor has the greatest impact on the decision-making criteria:}

To investigate the effect of financial benefits we used the multiple linear regression analysis methods. The resource-based view and cost reduction, the effect three factors are analyzed. The

InTraders International Trade Academic Journal Vol.4 Iss.2 e-ISSN-2667-4408

www.intraders.org 
assumptions for multiple linear regression analysis (normality, linearity, and equality of variances) were fulfilled by data. There was no change in the dependent variable. The value of ANOVA was investigated in the model of making criteria. The model of ANOVA (identity of the population model summary) satisfied all the assumptions.

A post hoc analysis was done using Tukey's range test and results identify that the differences test was significantly conducted. The value of regression is 0.000 which is less than the significant value of $\mathrm{a}<0.05$. The adjusted $\mathrm{r}$ square value is .980 which shows a high impact of an independent variable on a dependent variable although, there is a significant impact of the Resource-based view on making criteria.

Table 2

\section{Regression Analysis}

\begin{tabular}{lll} 
Making Decision Criteria & Coefficient & Sig Value \\
\hline Resource-Based View & .497 & 0.000 \\
Financial Benefit & -.275 & .412 \\
Cost Reduction & .139 & .654 \\
& -.275 & .341
\end{tabular}

Regression analysis shows that Resource-based reviews have a high impact on the decisionmaking criteria. While taking the make and buy decision the resource-based view is the most important factor.

\section{Conclusions}

In a highly competitive market, organizations strive to prepare for future schemes that will assist them in enhancing organizational success. Such processes assist businesses in gaining a competitive edge. Pharmaceutical companies in the competing and challenging marketplace can lower costs by reducing the cost of practices. The results depict that in Pakistan most of the InTraders International Trade Academic Journal Vol.4 Iss.2 e-ISSN-2667-4408 
pharmaceutical companies are using the Make in-house activity in business. The companies' major motive behind making is cost-efficiency. The results of the correlation show that there is a significant influence of resource-based view, especially on cost reduction of companies. Cost is a prominent factor that has a significant impact on the company's manufacturing under rule 1948 of Pakistan. The pharmaceutical industry also prefers making because they have all resources.

In the end, the results show that these financial benefits, Resource-based view, and cost reduction have a highly significant positive relationship with making criteria.

As the respondent also told that the core part includes all types of medicine that should be made by the Albert pharmaceutical industry. It is also a government requirement because a report of medicine which chemical and drug users and what are its effect should be submitted to the Drug Regulatory authority of Pakistan (DRAP). All medicine that is made required a specific temperature and environment that's why the core part is also made. Non-core parts which are packing material, Logistics, bottles for syrup, and logo prints are outsourced. After the approval of the government, medicine should be made and sale to the consumer. Regression analysis shows that Resource-based review has a high impact on "making" criteria. As we conclude while taking the make and buy decision the resource-based view is an important factor. In light of the above fact, pharmaceutical companies give a positive impact of Resource-based review on decision-making criteria and Efficiency increases. In the end, the results concluded that due to several reasons as The Albert pharmaceutical industry prefers making criteria. ON their resources base they prefer to make because they have all resources needed for making medicine as well as it is cost-effective in Pakistan.

\section{Limitations and future research direction}

Our research is limited to the Albert Pharmaceutical industry due to shortage of time we have limited data for finding so all this research is according to one pharmaceutical industry. As a student or due to a pandemic we could not have approached other pharmaceutical industries. Another limitation is the sample size this research is also conducted by increasing the sample size. Future research can be done by increasing the number of pharmaceutical industries and any other industries.

InTraders International Trade Academic Journal Vol.4 Iss.2 e-ISSN-2667-4408

www.intraders.org 


\section{References}

Arya, A., Mittendorf, B., \& Sappington, D. E. (2008). The make-or-buy decision in the presence of a rival: strategic outsourcing to a common supplier. Management Science, 54(10), 1747-1758.

Akeem, L. B. (2017). Effect of cost control and cost reduction techniques in organizational performance. International business and management, 14(3), 19-26.

Barney, J. (1991). Firm resources and sustained competitive advantage. Journal of Management, 17(1), 99-120.

Bastani, P., Ghanbarzadegan, A., Vatankhah, S., \& Samadbeik, M. (2019). Components affecting pharmaceutical strategic purchasing: a scoping review. Health services insights, 12, 1178632919837629.

Bartel, A. P., Lach, S., \& Sicherman, N. (2014). Technological change and the make-or-buy decision. The Journal of Law, Economics, \& Organization, 30(1), 165-192.

Cánez, L. E., Platts, K. W., \& Probert, D. R. (2000). Developing a framework for make-or-buy decisions. International Journal of Operations \& Production Management.

Davis, E. W. (1992). Global outsourcing: have US managers thrown the baby out with the bathwater? Business Horizons, 35(4), 58-66.

Hsiao, H., Kemp, R., van der Vorst, J. G., \& Omta, S. (2009). Make-or-buy decisions and levels of logistics outsourcing: an empirical analysis in the food manufacturing industry. Journal on Chain and Network Science, 9(2), 105-118.

Hingorani, N. L., \& Ramanathan, A. R. (1973). Management Accounting, New Delhi: S. Chand $\&$ Sons.

Hampton, J. J. (1986). Corporate Finance Using Electronic Spreadsheets, Prentice-Hall.

Hafeez, A., \& Andersen, O. (2014). Factors influencing accounting outsourcing practices among SMEs in Pakistan context: Transaction cost economics (TCE) and resource-based views (RBV) prospective.

Joseph, K., \& Kalwani, M. U. (1995). The impact of environmental uncertainty on the design of salesforce compensation plans. Marketing Letters, 6(3), 183-197.

InTraders International Trade Academic Journal Vol.4 Iss.2 e-ISSN-2667-4408

www.intraders.org 
Mohamed, Z. A., Abdullah, H. H., Othman, R., \& Uli, J. (2009). Make or buy strategy and origin of sourcing materials and their relationship with firm performance. International Review of Business Research Papers, 5(3), 142-155.

McIvor, R. T., Humphreys, P. K., \& McAleer, W. E. (1997). A strategic model for the formulation of an effective makes or buy decision. Management Decision.

McIvor, R. (2000). A practical framework for understanding the outsourcing process. Supply Chain Management: an international journal.

Moschuris, S. J. (2015). Decision-making criteria in tactical make-or-buy issues: an empirical analysis. EuroMed Journal of Business.

Neves, L. W. D. A., Hamacher, S., \& Scavarda, L. F. (2014). Outsourcing from the perspectives of TCE and RBV: A multiple case study. Production, 24(3), 687-699.

Platts, K. W., Probert, D. R., \& Canez, L. (2002). Make vs. buy decisions: A process incorporating multi-attribute decision-making. International journal of production economics, 77(3), 247-257.

Padillo, J. M., \& Diaby, M. (1999). A multiple-criteria decision methodology for the make-orbuy problem. International Journal of Production Research, 37(14), 3203-3229.

Premkumar, G., Ramamurthy, K., \& Saunders, C. S. (2005). Information processing view of organizations: an exploratory examination of fit in the context of inter-organizational relationships. Journal of Management Information Systems, 22(1), 257-294.

Pandey, I. M. (1992). Venture capital and entrepreneurial development: The Indian experience.s

Rogers, B. (2009). An exploratory study of the make-or-buy decisions in pharmaceutical sales. Journal of Medical Marketing, 9(1), 11-20.

Rasheed, H., Hoellein, L., Bukhari, K. S., \& Holzgrabe, U. (2019). Regulatory framework in Pakistan: situation analysis of medicine quality and future recommendations. Journal of pharmaceutical policy and practice, 12(1), 1-15.

InTraders International Trade Academic Journal Vol.4 Iss.2 e-ISSN-2667-4408

www.intraders.org 
Sun, S. Y., Hsu, M. H., \& Hwang, W. J. (2009). The impact of alignment between supply chain strategy and environmental uncertainty on SCM performance. Supply Chain Management: An International Journal.

Tayles, M., \& Drury, C. (2001). Moving from make/buy to strategic sourcing: the outsourcing decision process. Long-range planning, 34(5), 605-622. 